\title{
Expression of the trk proto-oncogene is restricted to the sensory cranial and spinal ganglia of neural crest origin in mouse development
}

\author{
Dionisio Martin-Zanca, Mariano Barbacid, ${ }^{1,2}$ and Luis F. Parada ${ }^{3}$ \\ Molecular Embryology Group and 'Developmental Oncology Section, BRI-Basic Research Program, National Cancer \\ Institute-Frederick Cancer Research Facility, Frederick, Maryland 21701 USA
}

\begin{abstract}
We have cloned and characterized the mouse homolog of the human trk proto-oncogene, a member of the protein tyrosine kinase (TK) receptor gene family. Here, we present the first report of a trk-encoded mRNA species in vivo. In situ hybridization analysis in the mouse embryo reveals a striking temporal and spatial regulation of $t r k$ transcription, with expression confined to the sensory cranial (trigeminal, superior, jugular) and dorsal root ganglia (DRG) of neural crest origin. Recent reports have shown that TK receptors can play regulatory roles in embryonic development. Thus, the developmental mutations $W$ in mouse and torso and sevenless in Drosophila represent genes that code for defective TK receptors. Our data show that trk, a gene associated with malignancy in humans, is a specific marker for a set of neural crest-derived sensory neurons, and are consistent with the hypothesis that this proto-oncogene may have an important role in the development or phenotype of the neurons where it is expressed.
\end{abstract}

[Key Words: Developmental expression; in situ hybridization; proto-oncogene; trk; tyrosine kinase receptor]

Received January 31, 1990; revised version accepted March 8, 1990.

The elegant classical body of work on the developing vertebrate embryo has provided an essential framework for more recent studies on the molecular basis of development. Various approaches have been applied to the search for genes that are potential regulators of mammalian development. One method has been to clone and study the mammalian homologs of genes known to have developmental functions in invertebrates. An example is provided by the study of homeotic genes (first identified in Drosophila melanogaster) in mouse and man, which has resulted in the identification of many loci that present unique expression profiles in the embryo (Jackson et al. 1985; Joyner et al. 1985; Awgulewitsch et al. 1986; Holland and Hogan 1988; Dollé et al. 1989; Wilkinson et al. 1989). Another fruitful method for identifying genes with potential roles in embryogenesis stems from work with oncogenes. Investigators in this field have identified and isolated a diverse series of genes that, when structurally mutated or inappropriately expressed, have the common property of exerting profound effects on the regulation of cell proliferation (Land et al. 1983; Weinberg 1985; Bishop 1987). It has further emerged that many proto-oncogenes form part of highly conserved gene families and, at least in some cases, are either exclusively expressed or tightly regulated during embryogenesis (Jakobovits et al. 1985, 1986; Zim-

2Present address: Squibb Institute for Medical Research, Department of Molecular Biology, Princeton, New Jersey 08543-4000 USA.

${ }^{3}$ Corresponding author. merman et al. 1986; Wilkinson et al. 1987, 1988; R. Klein, D. Martin-Zanca, M. Barbacid, and L.F. Parada, in press|, leading to the suggestion that proto-oncogenes may have important roles in development (Muller 1986; Nusse 1988).

The tyrosine kinase (TK) receptor proto-oncogenes comprise a large family of structurally related genes whose products mediate proliferation and differentiation control signals in a variety of cell types (for review, see Hanks et al. 1988). Recently, TK receptors have also been implicated in the control of embryonic cell fate decisions. The $W$ locus in mouse codes for the c-kit protooncogene, a TK receptor that is required for the effective migration and proliferation of various stem cells in the embryo and in the adult (Silvers 1979; Yarden et al. 1987; Chabot et al. 1988; Geissler et al. 1988). In Drosophila, the torso and sevenless loci encode TK receptors that are required for terminal structure differentiation and photoreceptor morphogenesis, respectively (Basler and Hafen 1988; Sprenger et al. 1988). Here, we report the molecular cloning and developmental expression profile of the mouse trk proto-oncogene. The human trk oncogene was originally identified following transfection of NIH-3T3 cells with DNA obtained from a human colon carcinoma and remains the only example of a TK oncogene activated in a solid human tumor (Pulciani et al. 1982; Martin-Zanca et al. 1986a). Subsequent isolation and structural characterization of both the oncogene and proto-oncogene cDNAs identified a gene 
product containing all the structural motifs of a transmembrane receptor (Martin-Zanca et al. 1986a, 1989; see Fig. 1A). Oncogenic activation of trk occurred via a somatic genetic rearrangement that resulted in the replacement of the trk receptor extracellular domain by the amino-terminal region of a nonmuscle tropomyosin molecule. As has been proposed for other members of the family of transmembrane receptors, the trk gene product apparently becomes transforming through the disruption of its signal-receiving extracellular domain, resulting in the constitutive activation of the signaltransducing intracellular domain (Downward et al. 1984; Bargmann et al. 1986; Park et al. 1986; Roussel et al. 1987; Coulier et al. 1989). Northern blot analysis with a human $t r k$ cDNA probe revealed an extremely restricted pattern of expression for this gene in mRNAs from human cell lines and tissues. Abundant levels of trk transcripts were found only in a limited number of human tumor cell lines of diverse tissue origins (MartinZanca et al. 1986b). These data did not provide any useful clues about the in vivo specificity of trk expression. In a survey of RNA from human tissues, extremely low levels of trk mRNA were seen only in testes (unpubl.), an observation whose physiological relevance remains unclear. In contrast, a complex pattern of mRNA species was detected when the human trk cDNA probe was hybridized to adult mouse brain RNA. Studies based on this latter observation have led to the identification of a closely related gene, trkB (Klein et al. 1989, and in press).

The failure to detect $t r k$-encoded transcripts in adult tissues prompted us to explore whether this gene was transcribed in the embryo. For this purpose, we have cloned and characterized the mouse trk locus. After generating exonic probes, we have performed developmental Northern blot and in situ hybridization analyses of the mouse $t r k$ proto-oncogene from early postimplantation through late fetal development. We detect the appearance of a trk-encoded mRNA in the embryo and show a striking temporal and spatial regulation of trk transcription. These data identify trk as the earliest known marker for dorsal root ganglia (DRG) and cranial sensory ganglia of neural crest origin.

\section{Results}

Isolation of the mouse gene homologous to the human trk proto-oncogene

To isolate the mouse homolog to the human trk protooncogene, a genomic library from NIH-3T3 cells was

A

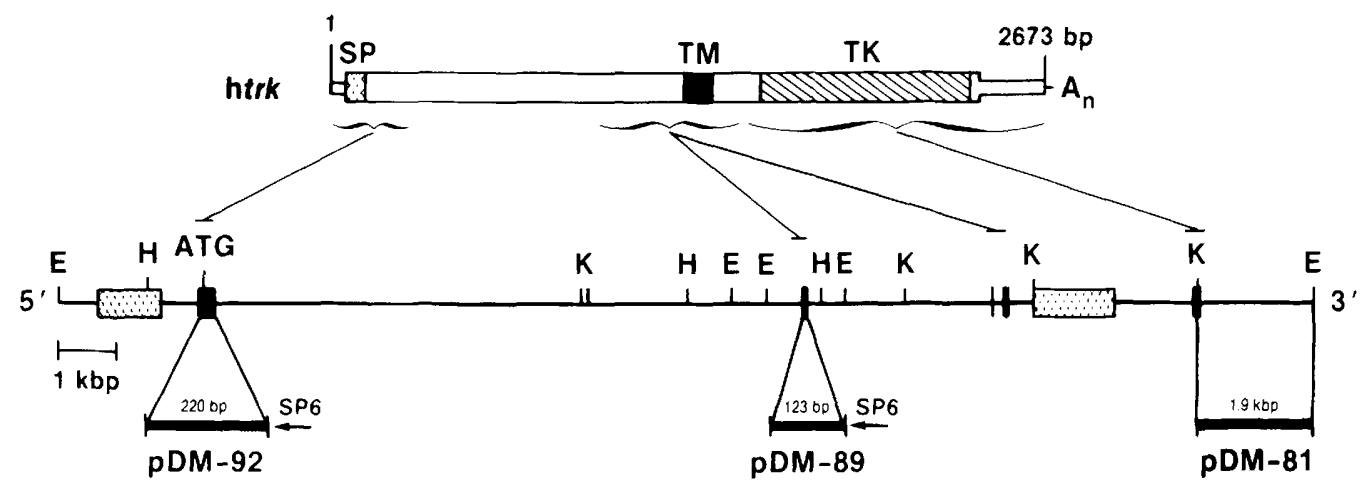

Figure 1. (A) Schematic representation of human and mouse trk proto-oncogene clones. (htrk) Structure of the human trk cDNA (Martin-Zanca et al. 1989). Thick bar represents coding sequences. (SP) Signal peptide; (TM) transmembrane domain; (TK) tyrosine kinase catalytic domain. Brackets indicate cDNA probes used to identify trk exons in the mouse trk clone shown below. ( $\lambda 18 \mathrm{~m} t r k)$ Partial restriction map of a mouse trk genomic $\lambda$ clone. Crossbars represent DNA fragments containing mouse repetitive sequences. Solid boxes indicate trk exons. Also shown are the mouse trk probes used for Southern blots (pDM-81) and for Northern and in situ hybridizations (pDM-89, pDM-92) (for details, see Methods). The 1-kb scale bar corresponds to the genomic clone $\lambda 18 \mathrm{~m} t r k$. ( $B$ and $C$ ) Southern blot analysis of mouse tail $(\mathrm{M})$ and human HeLa cell $(\mathrm{H})$ DNAs. DNAs $(5 \mu \mathrm{g})$ isolated from human HeLa cells or C57BL/6J mouse tails were digested with BamHI or HindIII restriction enzymes, electrophoresed through $1 \%$ agarose gels, and transferred to filters (for details, see Methods). Mouse DNA restriction fragments hybridizing with both the human $(B)$ and mouse (C) trk probes are indicated by arrowheads. Molecular weight markers (left) correspond to coelectrophoresed $\lambda$ HindIII restriction fragments.
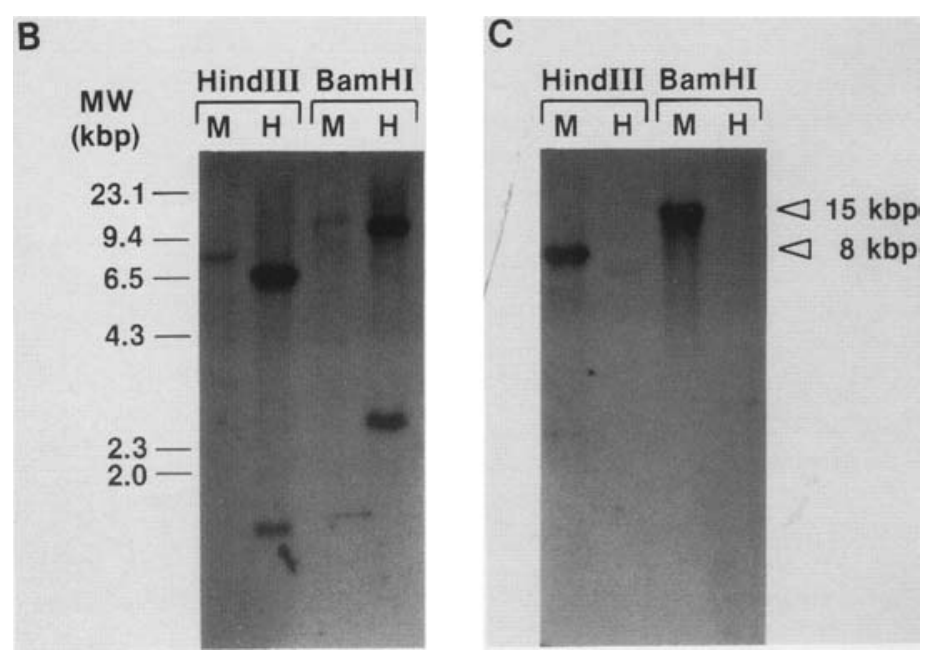
screened with the entire human trk cDNA as probe. Southern blot analysis showed that under the appropriate hybridization conditions (see Methods), the human cDNA probe hybridized strongly with a $15-\mathrm{kb}$ BamHI mouse genomic fragment (Fig. 1B) and weakly with another fragment of $\sim 6 \mathrm{~kb}$ (not seen in Fig. 1B). Two overlapping $\lambda$ clones, containing DNA inserts $\sim 20$ $\mathrm{kb}$ in length, were isolated and purified. A partial restriction map of the trk clone extending furthest $5^{\prime}$ is shown in Figure 1A.

To demonstrate that the genomic clones represented the mouse trk locus and not a related locus (Klein et al. 1989|, fragments lacking repetitive sequences were identified, subcloned, and used as probes in Southern transfer analysis of mouse and human DNAs. In the Southern blots shown in Figure 1, probes that corresponded to the same coding regions from the human cDNA and from the mouse genomic clones (human TK probe and mouse probe pDM-81; Fig. 1A) were hybridized under stringent conditions to mouse and human DNAs digested with the restriction endonucleases HindIII or BamHI. The resulting pattern of hybridization identifies single restriction fragments $(15-\mathrm{kb} B a m H I$ and 8-kb HindIII; Fig. 1B,C) in mouse DNA when either the exonic mouse probe or the more complex human cDNA probe was used. However, the human DNA lanes exhibit a different profile of hybridization (Fig. 1B). As expected, in this latter instance, the mouse probe recognizes single restriction fragments that comprise only a subset of those hybridized by the human probe. Similar results were obtained when probes from other regions of the human trk cDNA and from the corresponding mouse exonic sequences were tested (not shown).

Exon-containing genomic DNA fragments were identified by hybridization with probes corresponding to the three main domains of the human trk gene product: namely, the extracellular, transmembrane, and TK domains (Fig. 1A). Candidate fragments were subcloned, and subsequent partial sequence analysis of these subclones allowed us to identify and tentatively map several mouse trk exons (Fig. 1A). DNA sequence comparison of putative exonic mouse sequences with the corresponding regions of the human trk cDNA revealed a high level of identity in all cases, ranging from $>90 \%$ in the TK domain to $>80 \%$ in all other domains (in prep.).

\section{Northern analysis of trk expression in mouse embryonic RNAs}

Two of the putative exons thus defined were selected to generate probes for use in Northern analysis and in situ hybridizations (see Methods). These probes were chosen from regions outside the TK domain of mouse trk to avoid recognition with other members of the TK family of genes, particularly with the closely related trkB gene (Klein et al. 1989). We were concerned that the small exonic components of pDM89 and pDM92 (Fig. 1A) would not provide enough probe sequence complexity to recognize the presence of a low-abundance trk transcript. We therefore used both plasmid inserts together, but labeled independently, as probes in a Northern analysis performed with total mouse embryo RNA. The result of this experiment is shown in Figure 2. The first appearance of trk transcripts was observed at E9.5 as a single, 3.2-kb species. The intensity of the trk-specific band increases to a maximum level at E13.5 followed by a decrease such that it is no longer detectable in adult tissues (not shown). The same filter was hybridized with a $\beta$-actin probe to assess the relative amounts of RNA loaded in each lane, and the results are shown in Figure 2. We also tested for trk expression in embryonic stem (ES) cells and failed to detect transcripts (Fig. 2). ES cells are derived from the inner cell mass of the mouse blastocyst and may thus be considered representative of a component of the late blastocyst (E4.5), which can participate in normal development when reintroduced into early embryos (for review, see Robertson 1987). This result is consistent with the observed expression in embryonic RNAs.

Therefore, at the resolution provided by our Northern analysis, the trk gene is not expressed in preneurulation embryos through 8.5 days of gestation (stage E8.5). The appearance of trk-specific transcripts coincides with the timing of cephalization, neural crest migration, spinal ganglia formation, and the morphogenesis of most cranial ganglia. Thus, trk mRNA appearance in the mouse

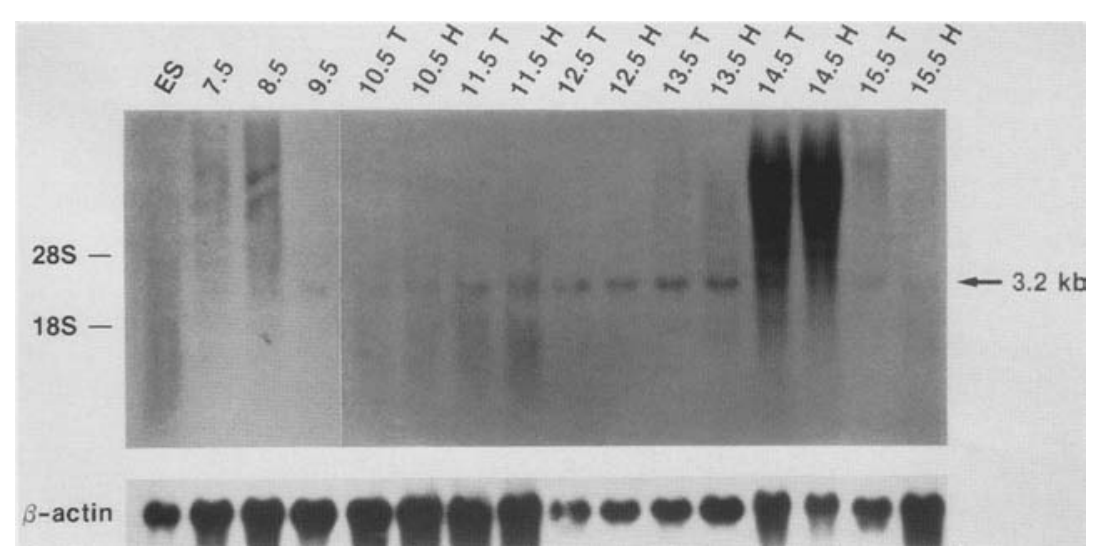

Figure 2. Northern blot hybridization of total embryo RNA with mouse genomic trk probes pDM89 and pDM92. Above each lane the gestation ages of the embryo samples are indicated, as well as the origin $[(\mathrm{H})$ head; $(\mathrm{T})$ trunk] of the RNAs. (Lane ES) Total RNA from the ES cell line CPl. Migration of the 3.2-kb trk-specific mRNA (arrow) and of the $28 \mathrm{~S}$ and $18 \mathrm{~S}$ rRNAs are indicated. Samples in lanes labeled ES, $8.5,14.5 \mathrm{~T}$, and $14.5 \mathrm{H}$ are contaminated with embryo DNA, seen as a high-molecularweight smear. (Bottom) Hybridization of the same filter with a chicken $\beta$-actin cDNA probe. 
embryo coincides with major morphogenic events in the developing nervous system.

trk is expressed in sensory ganglia of the peripheral nervous system

Having ascertained that trk was expressed in the embryo, we performed in situ hybridization analysis on sections prepared from mouse embryos to determine the spatial distribution of transcripts in search of clues about its function. We began our analysis by using sections from the developmental stages (E12.5-E14.5) that demonstrated highest expression, as seen in Figure 2, and extended the analysis to include all stages that had been tested by Northern analysis. No trk-specific labeling was detected in embryo sections prior to E9.5 (data not shown), which coincides with the results seen in Figure 2.

By E9.5, when a trk-hybridizing band is first seen by Northern analysis (Fig. 2), morphogenesis of the peripheral nervous system (PNS) has commenced and the DRG are condensing from the migrated neural crest lateral to the neural tube. Appearance of trk labeling begins here, in embryo sections, as a faint but reproducible signal that is associated with the site of condensing DRG (Fig. $3 \mathrm{~A}-\mathrm{C})$. This trk-specific labeling of the spinal ganglia is even more apparent a day later in gestation (E10.5) when the fusiform, but distinct, spinal ganglia are clearly labeled (Fig. 3D-G). As development proceeds, and organogenesis unfolds, the cell-type complexity in the embryo increases, but trk expression remains restricted to the same components of the developing PNS.

trk $m R N A$ levels remain constant during late development

By 13.5 days of gestation, the embryo is at a stage when the major organs are formed and easily discernible. The trk mRNA levels reach a peak at this stage, as shown by Northern analysis (Fig. 2). We therefore hybridized diverse sections of the embryo to search for additional sites of trk transcript that may account for the observed increase in levels of mRNA. Figure 4, A and B, shows a parasagittal section through an entire E13.5 embryo, demonstrating strong labeling of the ganglion of the fifth cranial nerve (trigeminal). The acoustic ganglion (VIII), a sensory ganglion derived from the otic placode (Le Douarin 1982), is visualized in the same section and does not express the trk gene at this stage (see arrowhead in Fig. 4B). Higher magnification (Fig. 4C,D) shows the trigeminal nerve arriving into the ganglion from the base of the myelencephalon $\left({ }^{*}\right)$ and the emanating nerve that will branch toward diverse facial structures; neither nerve bundle contains detectable trk transcripts, indicating the exclusive trk transcription within the cells of the trigeminal ganglion and the exclusion of these mRNAs from the nerve processes.

The specificity of $t r k$ transcription for DRG and its scope of expression along the craniocaudal axis is illustrated in Figures 5 and 6 for lumbar and cervical DRG.
In Figure 5, A and B, light- and dark-field views of a frontal section through an E14 embryo are shown. The only DRG visible, at the level of the metanephros, are labeled by the trk probe, whereas the circumscribed spinal cord and the brain, in addition to various nonneuronal organs, are not labeled. Figure 6, A and B, affords a closer view of the hybridizing region. A sagittal section through an E14.0 embryo (Fig. 5C,D) also provides a view of various neuronal and nonneuronal structures that do not express trk; notably, neither the inferior ninth and tenth (petrosal and nodose) cranial ganglia nor the various brain folds (telencephalon, mesencephalon, and myelencephalon) display any reactivity with the trk probe. Dorsally, below the myelencephalon, the cranial-most DRG is seen, and is the only structure in this plate expressing trk. The hybridizing region is magnified in Figure 6, C and D. We have hybridized representative frontal sections that permitted analysis through various ventral-dorsal levels. This analysis confirmed the presence of trk messenger in apparently all DRG, but the absence of expression in other neuronal structures, such as brain, optic nerve, retina, and visceral and somatic motor cranial ganglia. Summary of the data indicates that trk expression is confined to visceral sensory ganglia, including the superior ninth and tenth cranial (superior and jugular; see Fig. 7) ganglia, which are also of neural crest origin.

We then extended this analysis for trk expression through the remaining stages of fetal development and observed no deviation from the patterns already described. Examples of expression in late-stage embryos are shown in Figure 7. Figure 7, A and B, shows a midsagittal section through the head region of an E17.5 embryo, which brings to view the cranial-most DRG (that form the cervical and brachial plexuses) and various sensory and motor cranial ganglia, including the fifth, seventh, eighth, and ninth/tenth inferior and superior complexes. Only sensory, crest-derived structures (DRG, fifth, and superior ninth/tenth ganglia) maintain trk expression. Finally, a frontal view of an E17.5 embryo (Fig. $5 \mathrm{C}, \mathrm{D})$ illustrates continued trk expression in DRG along the entire length of the spinal chord at this late stage. Thus, cranial ganglia that are not strictly sensory, such as the inferior ganglia of the ninth and tenth nerves (petrosal and nodose) and the facial (seventh) ganglion, or ganglia that are sensory but of placodal origin, like the acoustic (eighth) ganglion, do not express the trk gene. This designates the trk gene as a marker for a unique subset of ganglia and suggests the existence of neurons specific among these structures.

\section{Discussion}

In this study we report the molecular cloning, characterization, and developmental expression profile of the mouse trk proto-oncogene. Partial sequence and detailed Southern blot hybridization analysis allow us to conclude that the mouse trk gene is highly conserved along its entire coding region with the human counterpart, which contains an amino-terminal extracellular do- 

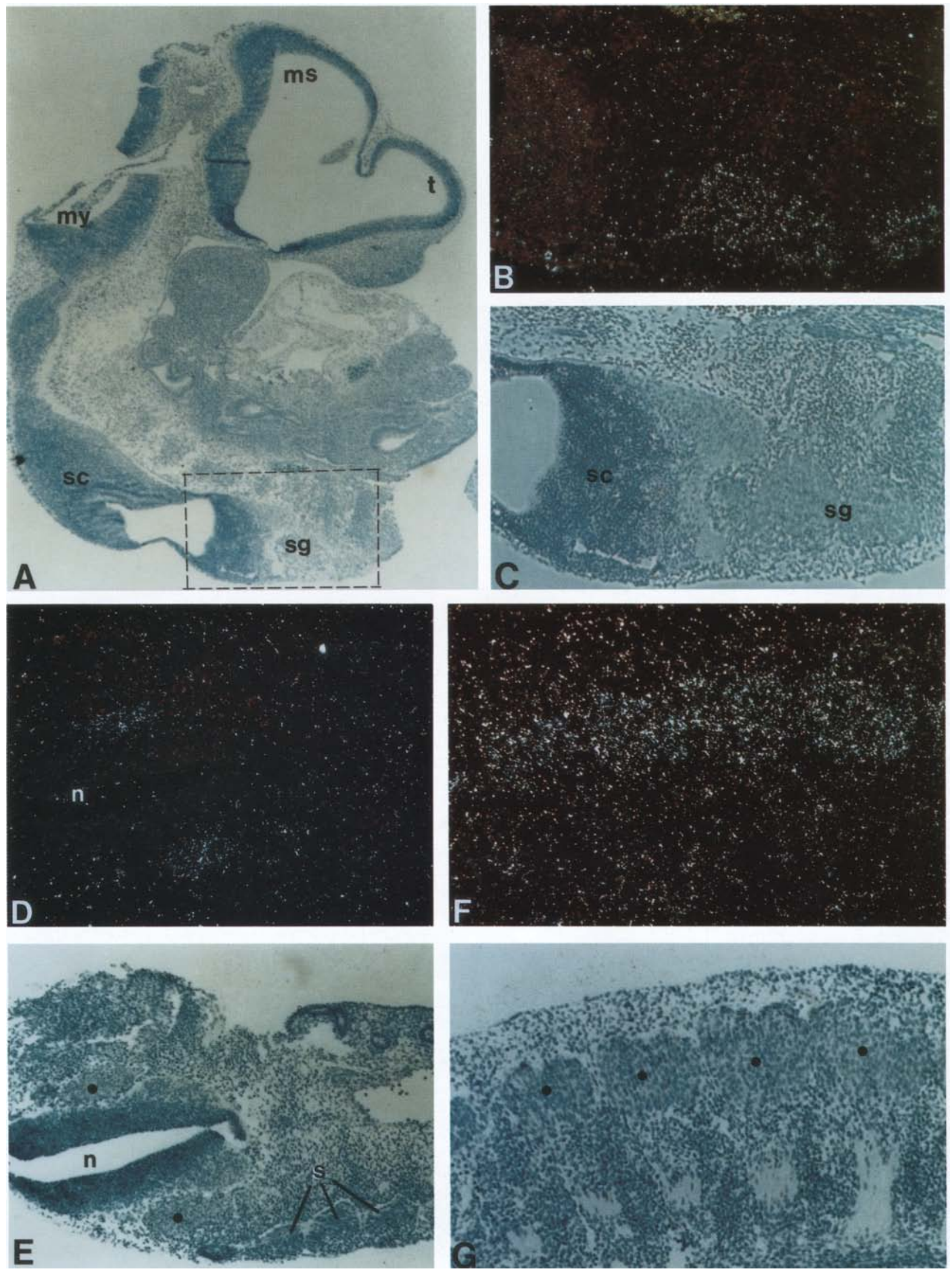

Figure 3. (See following page for legend.) 
main, a hydrophobic transmembrane domain, and a carboxy-terminal TK domain. Throughout development, the transcript for this gene is found exclusively in the sensory cranial and spinal ganglia of neural crest origin.

The developmental profiles of trk expression provided by the in situ data and by Northern analysis are in agreement. We are unable to detect $t r k$ mRNA in preneurulation stages, but once the neural crest component commences differentiation into spinal ganglia, a faint 3.2-kb band becomes apparent by Northern analysis (Fig. 2), which is reflected, by in situ hybridization, in a weak but distinct signal seen in condensing DRG of the corresponding embryo sections (Figs. 3 and 4). By E13.5, when the spinal and cranial ganglia have enlarged and represent a significant proportion of the embryo mass, the highest levels of trk are also visualized by Northern analysis (cf. Figs. 2 and 5), and, by in situ analysis, the labeling of the pre-eminent sensory cranial and spinal ganglia is high.

\section{trk transcription is maintained at high levels}

Extensive growth and development of the CNS and internal organs occurs in the late fetal stages, resulting in a differential growth that reduces the cranial and spinal ganglia to minor components of the total embryonic mass. This resulted in a decrease of signal for trk-specific transcripts by Northern analysis and gave the erroneous impression that trk expression diminished in late fetal stages. The use of in situ hybridization has allowed the localization of these transcripts and the demonstration that trk expression is sustained at similar levels in the same structures of the PNS throughout embryonic development.

During embryogenesis, the cells of the PNS undergo tremendous proliferation, migration, and differentiation. Once the ganglia are formed, nerve cell bodies and neural crest (pre-Schwann) cells extend and migrate, respectively, to the sites of innervation. It is possible that trk plays a role in one or several of these activities. We favor the notion that trk is expressed in neurons, and not in satellite, glial, or Schwann cells, for the following reasons. First, Schwann cells migrate along the axonal pathways in an undifferentiated, premitotic state. The presence of trk transcripts in these cells would be detected in our experiments as a highlighting of the axonal tract pathways - a feature that we have observed with the highly related trkB gene (Klein et al. 1989 and in press) but not with trk. Second, various cranial ganglia that do not express trk are populated by satellite cells of neural crest origin (i.e., the seventh, eighth, and inferior ninth/tenth complex; see Le Douarin 1982); therefore the distinguishing feature of the trk-positive ganglia is the origin and functionality of their neurons. Third, histological and tritiated thymidine studies in embryonic rat and mouse DRG indicate that proliferation of satellite cells within the spinal ganglia occurs after the proliferative stage of the neurons (i.e., after E15.0; Lawson et al. 1974; for references, see Altman and Bayer 1984). Thus, the considerable trk expression observed prior to E15.0 is arguably present in neurons; furthermore, no relative increase in expression is observed with the onset of satellite cell proliferation. Finally, preliminary in situ analysis of adult mouse cranial and spinal ganglia, where histological discrimination of cell types is unambiguous, indicates that expression is localized exclusively to neurons (D. Martin-Zanca and L.F. Parada, unpubl.). Thus, trk expression is maintained throughout the life of the organism, suggesting that whatever function trk has, it is not solely required in early embryogenesis.

\section{$T K$ receptors have developmental functions}

Until recently, TK receptors were primarily implicated in cell proliferation control, due mostly to the identification of many as growth factor receptors and also to the involvement of several of these genes in oncogenesis. Reports have now begun to emerge that implicate members of the TK receptor family in embryonic development. The $W$ locus in mouse encodes the c-kit proto-oncogene, a TK receptor (Yarden et al. 1987). Mutations at this locus have pleiotropic developmental effects, including sterility, anemia, and white coat color, which result from the malfunction of this receptor in the regulation of the proliferative and/or migratory capacity of melanoblasts, primordial germ cells, and hematopoietic stem cells (Silvers 1979; Chabot et al. 1988; Geissler et al. 1988). The Drosophila genes torso (Sprenger et al. 1989) and sevenless (Baneriee et al. 1987; Hafen et al. 1987; Basler and Hafen 1988) also encode TK receptors. The torso product is required for the terminal formation of the embryonic anterior and posterior structures, whereas sevenless is required for the morphogenesis of photoreceptor R7 in the retina. The structural similarities of the trk protein with torso and sevenless and with the protein products of the proto-oncogenes c-fms (CSF-1 receptor) and ErbB (EGF receptor) and the insulin receptor (Martin-Zanca et al. 1989), among others, support the notion that the trk protein may function as the receptor for a morphogenic, growth, or differentiation factor in the mouse PNS.

The neural crest of the early embryo gives rise to a diverse series of cell and tissue types in the adult, including the head skeleton and mesenchyme, melanincontaining pigment cells, sympathetic and parasympathetic ganglia of the autonomous nervous system, and, of particular interest here, dorsal root, trigeminal, jugular, and superior ganglia (Le Douarin 1982, 1986,

Figure 3. In situ hybridization of early postimplantation embryos with a trk probe. (A) Bright-field sagittal section of an E9.5 embryo. Dark-field $(B)$ and bright-field $(C)$ view of the boxed area in $A$. Dark-field $(D)$ and bright-field $(E)$ longitudinal view of an E10.5 tail section. Dark-field $(F)$ and bright-field $(G)$ sagittal view of the spinal ganglia in an E10.5 embryo. ( $t$ ) Telencephalon; (ms) mesencephalon; (my) myelencephalon; (sc) spinal cord; (sg) spinal ganglia; (n) neural canal; (s) somites; $(\cdot)$ spinal ganglia. 

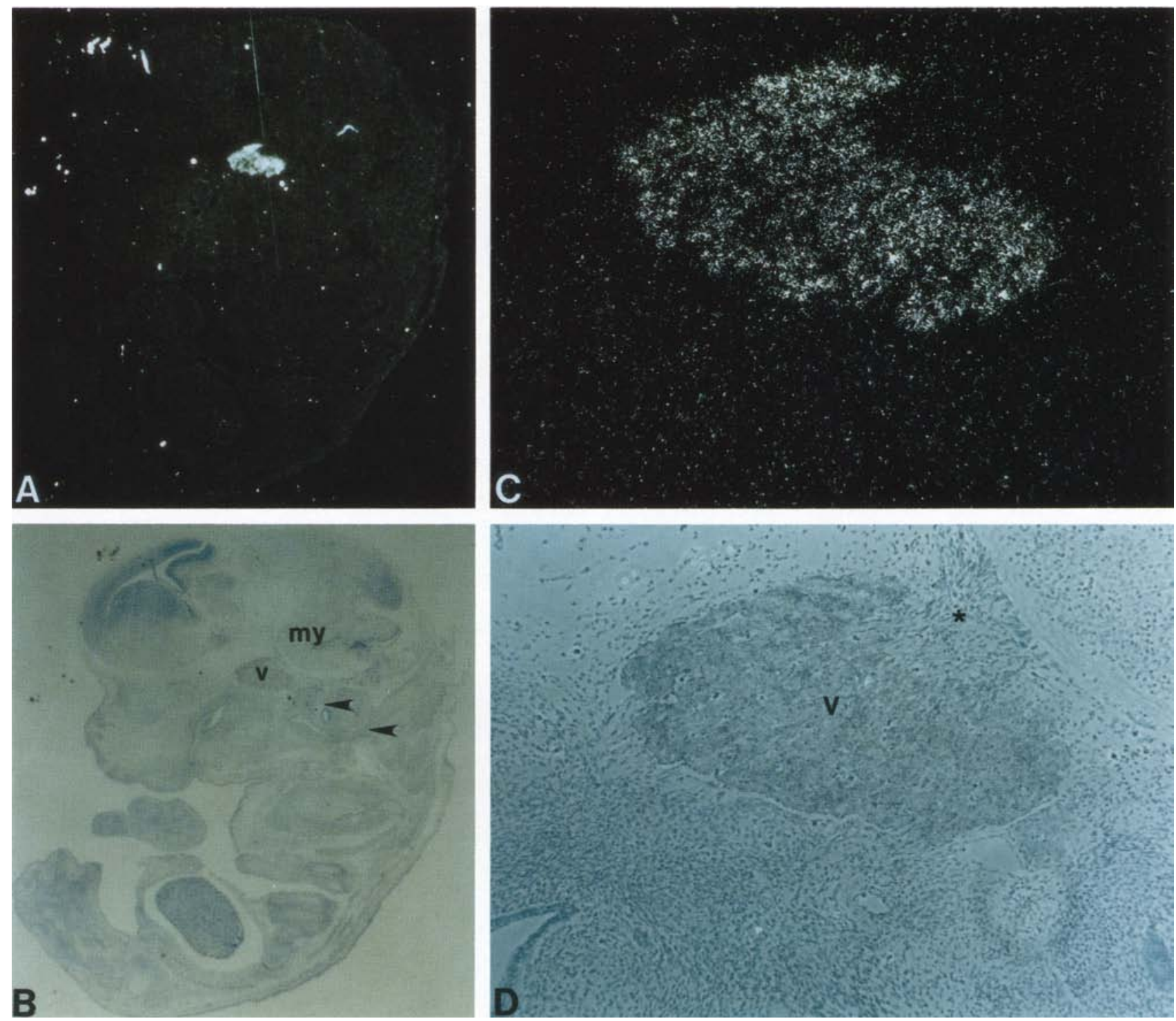

Figure 4. Expression of $t r k$ in trigeminal ganglion. Dark-field $(A)$ and bright-field $(B)$ view of a sagittal section from an E13.5 embryo. (V) Fifth ganglion; (my) myelencephalon. Arrowheads indicate acoustic and tenth ganglion. Dark-field $(C)$ and bright-field $(D)$ enlarged view of the trigeminal ganglion. $\left(^{\star}\right)$ Boundary cap abutting the myelencephalon.

Sieber-Blum 1989|. We show a specific and exclusive expression of a TK transmembrane receptor in these sensory ganglia early in development, whereas sensory ganglia of placodal origin (i.e., olfactory, optic, acoustic) do not express the trk gene. This work identifies the trk proto-oncogene as an early molecular marker for the sensory ganglia of cranial nerves $\mathrm{V}, \mathrm{IX}$, and $\mathrm{X}$ and for $\mathrm{DRG}$, suggesting the existence of cell types unique to these sensory neural-crest-derived structures. By analogy to other TK receptors with roles in embryogenesis, and in light of the tight regulation observed for this gene, it is possible that the trk protein performs an important function in the development and/or specific phenotype of neurons within these sensory ganglia.

\section{Methods}

Mice and embryos

Mouse embryos were derived from C57BL/6 NCR $\times \mathrm{C} 3 \mathrm{H} / \mathrm{HeN}$ $M T V-F_{2}$ litters. For RNA preparation and paraffin imbedding, embryos were staged under the dissecting microscope by counting somites through midgestation, and when somites were no longer visible in older embryos, external markers such as state-of-limb development were used (Theiler 1972). The morning of vaginal plug was considered day 0.5 (E0.5).

\section{In situ hybridization}

In situ hybridization protocols were as described (Hogan et al. 1986). Briefly, dissected embryos were fixed overnight in $4 \%$ 

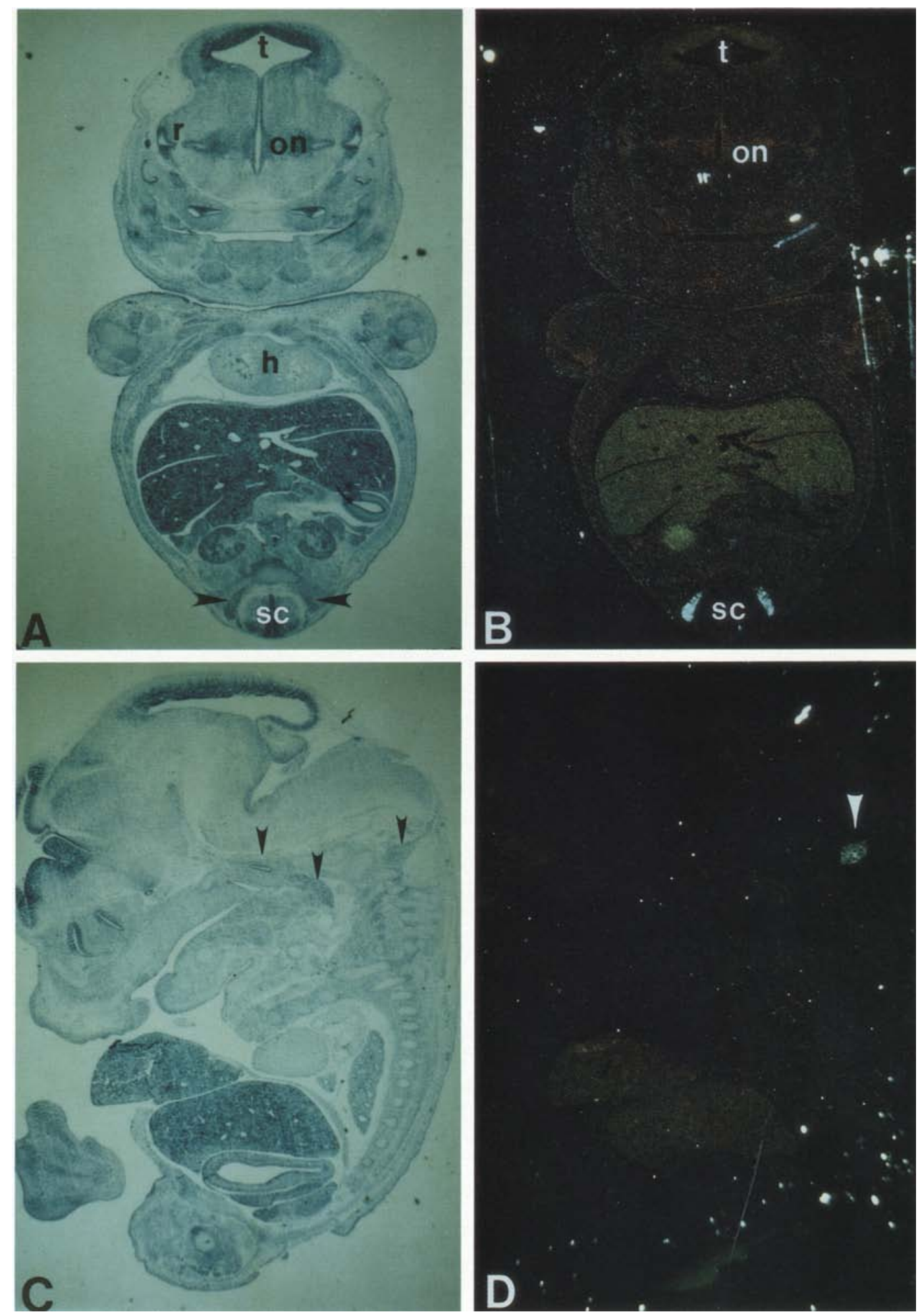

Figure 5. trk expression in caudal and rostral DRG. Bright-field $(A)$ and dark-field $(B)$ frontal section of an E13.5 embryo illustrating trk expression in the DRG at the level of embryonic kidney. $(\mathrm{t})$ Telencephalon; $(\mathrm{r})$ retina; (on) optic nerve; (h) heart; (sc) spinal cord. Arrowheads in $A$ indicate DRG (see also Fig. 6A,B). Bright-field $(C)$ and dark-field $(D)$ parasagittal views of an E13.5 embryo. Arrowheads in $C$ indicate cranial ganglia VIII, IX, and X (inferior complex) and the rostral-most DRG, which are also noted in $D$ (see also Fig. $6 \mathrm{C}, \mathrm{D})$. 

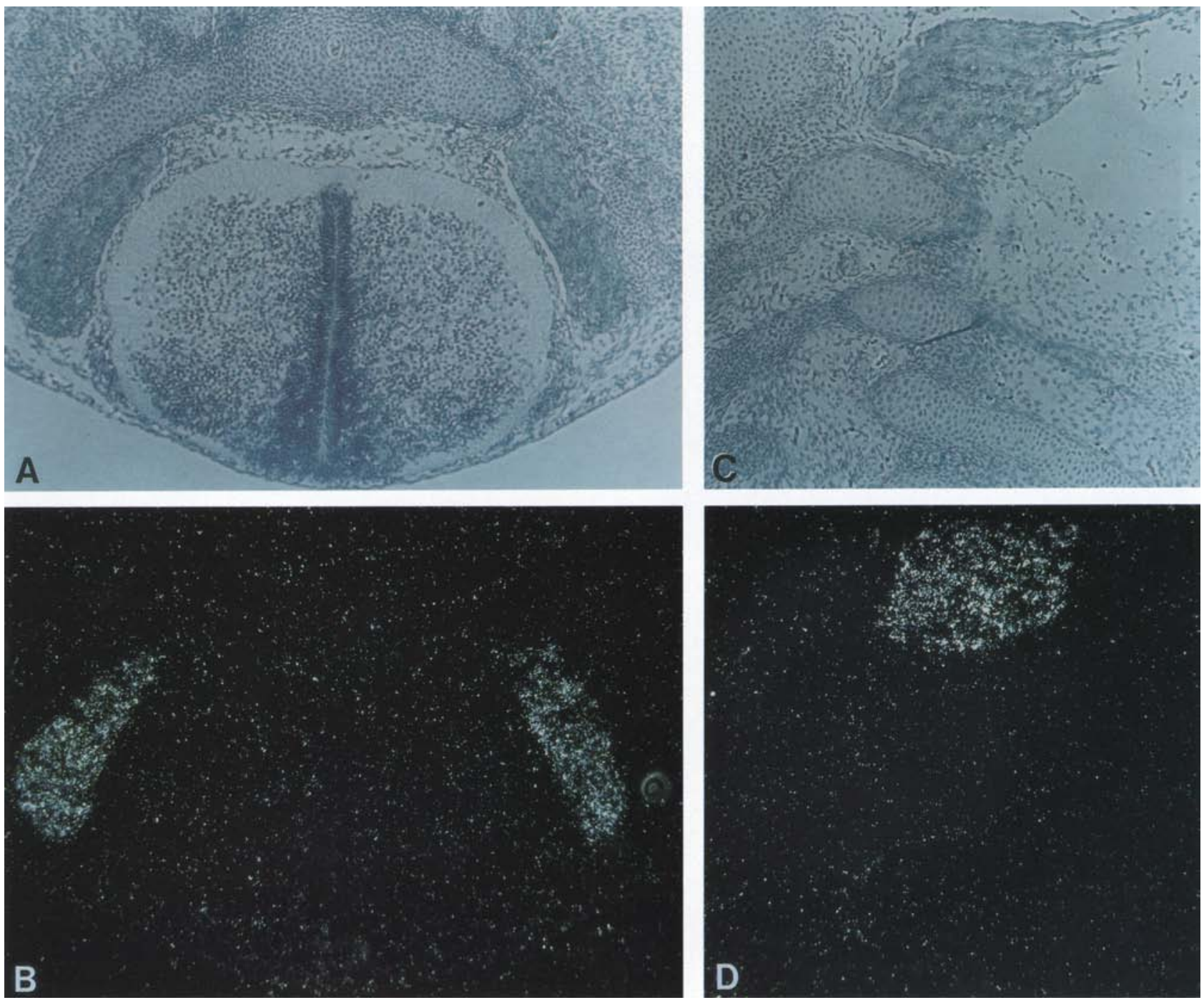

Figure 6. $t r k$ expression in DRG. Bright-field $(A)$ and dark-field $(B)$ are magnified views of the caudal DRG shown in Fig. 5 , A and B. $(C$ and $D)$ Magnified views of the cervical DRG shown in Fig. 5, C and D.

paraformaldehyde, dehydrated with alcohols and xylenes, and embedded in paraffin. Embryos were sectioned at 5- $\mu \mathrm{m}$ thickness and mounted on gelatin-coated slides. Slides were deparaffinized, digested with proteinase $\mathrm{K}$ (Boehringer-Mannheim), acetylated with triethanolamine, dehydrated, and hybridized overnight with $5 \times 10^{5} \mathrm{cpm}$ of ${ }^{35} \mathrm{~S}$-labeled riboprobe at $50^{\circ} \mathrm{C}$. The slides were washed in hybridization buffer at $37^{\circ} \mathrm{C}$ for several hours, treated with ribonucleases at $65^{\circ} \mathrm{C}$ for $30 \mathrm{~min}$, rinsed in $2 \times$ SSC, dehydrated, and dipped in Kodak emulsion NTB-2. After drying, the slides were stored for 8 days at $4^{\circ} \mathrm{C}$, developed in Kodak D-19, and fixed as recommended by the manufacturer. All dark- and bright-field photomicroscopy was done on a Zeiss Axiophot microscope. RNA probes labeled with ${ }^{35} \mathrm{~S}$ were prepared by standard procedures (Krieg and Melton 1987) by using either UTP or CTP (Amersham) as the labeled nucleotide.

The specificity of our trk probe is supported by the use of probes from different regions of the cDNA, which we have recently isolated from embryonic RNA. Furthermore, heterologous probes applied to sections adjacent to those presented here, including the related trkB gene, display distinct patterns of expression, recognizing different neuronal components (Klein et. al. 1989, and in prep.; D. Sassoon and L.F. Parada, in press).

\section{Southern transfer analysis}

DNAs $(5 \mu \mathrm{g})$ isolated from human HeLa cells or C57BL/6) mouse tails were digested with BamHI or HindIII restriction enzymes and electrophoresed through $1 \%$ agarose gels. Gels were irradiated with UV light $(\lambda=254 \mu \mathrm{m})$ for 4 min, soaked in alkali $(0.5 \mathrm{M} \mathrm{NaOH}, 1.5 \mathrm{M} \mathrm{NaCl})$ for $45 \mathrm{~min}$, and transferred to ZETABIND membranes (Cuno, Inc.), using the same alkali solution.

Probes were ${ }^{32} \mathrm{P}$-labeled either by nick-translation (Amersham kit) or by random priming procedures (BoehringerMannheim kit). Hybridizations were carried out at $65^{\circ} \mathrm{C}$ in $4 \times$ SSCP, $1 \times$ Denhardt's, and $1 \%$ SDS, when high stringency was required, or at $55^{\circ} \mathrm{C}$ in $5 \times \mathrm{SSCP}, 1 \times$ Denhardt's, and $1 \%$ SDS for low stringency. Filters were washed twice in $0.1 \times \mathrm{SSCP}$, 

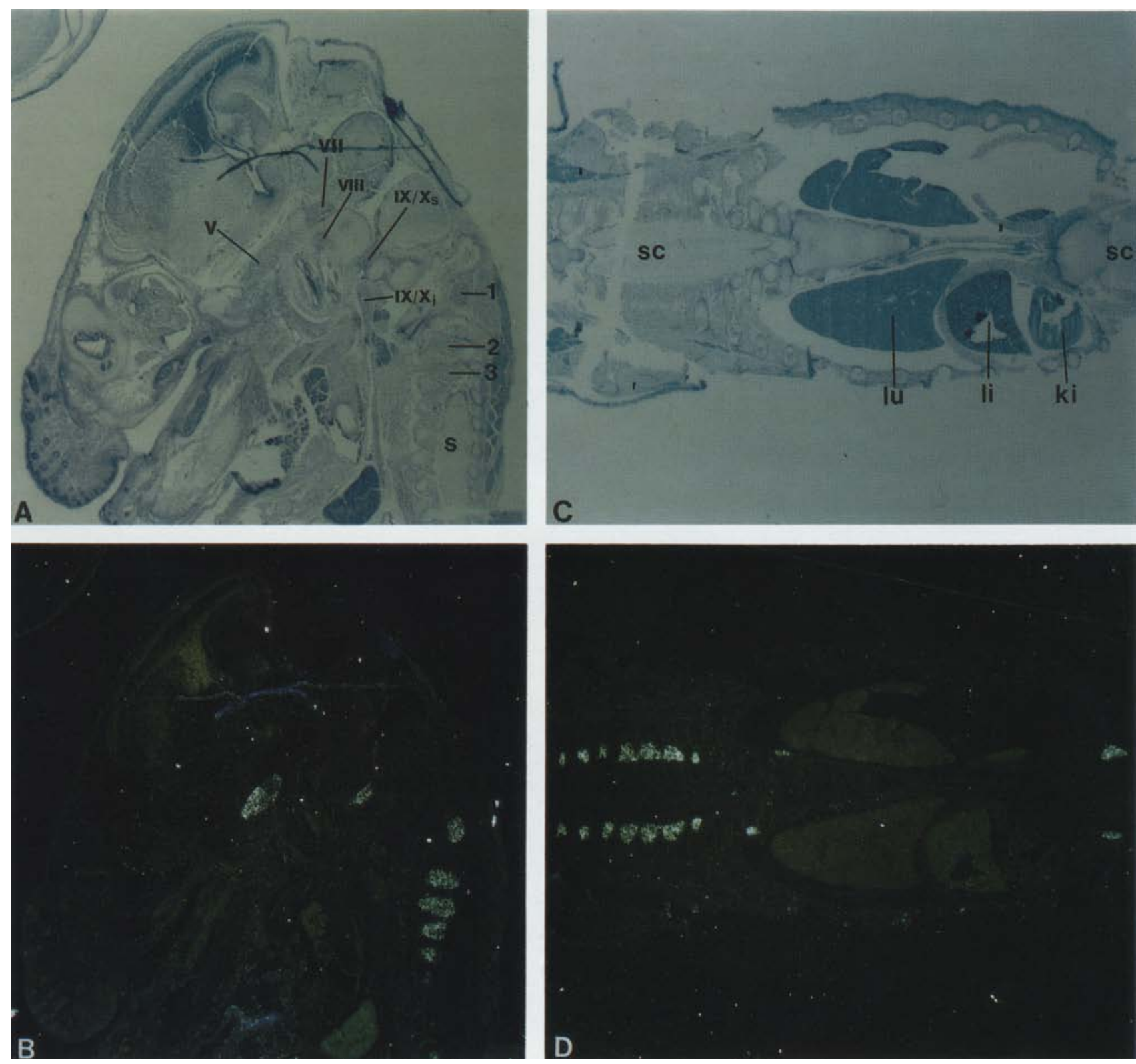

Figure 7. trk expression in late-stage embryos. $(A$ and $C)$ Bright-field views of E17.5 embryo sections, with corresponding dark-field views $(B$ and $D)$. (V) Fifth cranial ganglion; (VII) seventh cranial, (VIII) eighth cranial, $\left(\mathrm{IX} / \mathrm{X}_{\mathrm{s}}\right)$ ninth/tenth superior complex; $\left(\mathrm{IX} / \mathrm{X}_{\mathrm{i}}\right)$ ninth/tenth inferior complex. (1, 2, and 3) The first through third DRG (cervical plexus); (s and sc) spinal cord; (lu) lung; (li) liver; (ki) kidney.

$0.1 \%$ SDS at $65^{\circ} \mathrm{C}$, or in $0.2 \times \operatorname{SSCP}, 0.1 \%$ SDS at $55^{\circ} \mathrm{C}$, according to the stringency required.

\section{Library screening}

A genomic mouse NIH-3T3 library (from cells transformed with the human vav oncogene) (Katzav et al. 1989) was prepared. For this purpose NIH-3T3 DNA was partially digested with Sau3Al and fractionated in sucrose gradients. Fractions containing $15-$ to $22-\mathrm{kb}$-long DNA fragments were ligated to phage $\lambda E M B L-4$ arms (obtained by double digestion of this vector with the enzymes BamHI and SalI, followed by isopropanol precipitation). One and a half million recombinant phage $\lambda$ clones were hybridized with a nick-translated probe corre- sponding to the complete $2.7-\mathrm{kb}$ human trk proto-oncogene cDNA (Martin-Zanca et al. 1989) under conditions of moderate stringency $\left(42^{\circ} \mathrm{C}, 40 \%\right.$ formamide, $\left.5 \times \mathrm{SSC}\right)$. Filters were washed twice at $45^{\circ} \mathrm{C}$ in $0.1 \times \mathrm{SSC}, 0.1 \%$ SDS.

\section{RNA isolation and Northern analysis}

Embryos were dissected under the microscope, as detailed above, frozen in liquid nitrogen, and stored at $-70^{\circ} \mathrm{C}$. RNA was extracted by using RNAzol (Cinna/Biotecx) following the manufacturer's recommendations. For Northern analysis, $20 \mu \mathrm{g}$ of total RNA was electrophoresed through $1.2 \%$ agarose gels containing $0.37 \mathrm{M}$ formaldehyde, as described (Maniatis et al. 1982), transferred to ZETABIND membranes, and hybridized at $65^{\circ} \mathrm{C}$ 
according to Church and Gilbert (1984). Washes were carried out at $65^{\circ} \mathrm{C}$ in $0.5 \%$ BSA, $40 \mathrm{~mm}$ phosphate buffer $(\mathrm{pH} 7.2), 1 \%$ SDS.

\section{Construction of probes}

The trk-specific DNA fragments used for Northern analysis and in situ studies were inserted into SP6 or T7 promoter-containing plasmids such that antisense exonic sequences could serve as templates for RNA probes (Fig. 1A). pDM-81 contains a 1.9-kb KpnI-EcoRI fragment that hybridizes with the human TK domain. pDM-89 was generated by subcloning a 123-bp BgIII-HindIII DNA fragment, corresponding to a mouse trk exon $88 \%$ identical to nucleotides $814-934$ of the human trk proto-oncogene cDNA (Fig. 1A; Martin-Zanca et al. 1989), between the BamHI and HindIII sites of the vector pGEM-3Z (Promega). The BglII site located at the $5^{\prime}$ end of this exon occurs naturally, whereas the HindIII site located at the $3^{\prime}$ end was artificially introduced by DNA amplification using Taq polymerase (Mullis and Faloona 1987). The fidelity of the amplification was confirmed by sequencing of the resulting plasmid pDM-89 (not shown). pDM-92 was generated by subcloning of a blunt-ended 201-bp NarI DNA fragment, corresponding to a portion of the mouse trk first exon (Fig. 2A), into the HincII site of the vector pGEM-3Zf $\mid+$ ) (Promega).

\section{Acknowledgments}

We thank Gretchen White and Aliki Grammatikakis for their assistance with embryo preparations. Shula Katzav provided the mouse genomic library, and Jose-Luis Barredo assisted with screening. We are grateful to the members of the Mammalian Genetics Laboratory for their encouragement and discussions. We thank Tom Jessell for helpful discussions, Neal Copeland and Peter Donovan for critically reading the manuscript, and Robin Handley for help in its preparation. This research was supported by the National Cancer Institute, Department of Health and Human Services, under contract N01-CO-74101 with BRI. The NCI-Frederick Cancer Research Facility is fully accredited by the American Association for Accreditation of Laboratory Animal Care.

\section{References}

Altman. J. and S.A. Bayer. 1984. The development of the rat spinal cord. In Advances in anatomy, embryology, and cell biology, vol. 85. Springer-Verlag, Heidelberg.

Awgulewitsch, A., M.F. Utset, C.P. Hart, W. McGinnis, and F.H. Ruddle. 1986. Spatial restriction in expression of a mouse homeo box locus within the central nervous system. Nature 320: 328-335.

Banerjee, U., P.J. Renfranz, J.A. Pollock, and S. Benzer. 1987. Molecular characterization and expression of sevenless, a gene involved in neuronal pattern formation in the Drosophila eye. Cell 49: 281-291.

Bargmann, C.I., M.-C. Hung, and R.A. Weinberg. 1986. Multiple independent activations of the neu oncogene by a point mutation altering the transmembrane domain of p185. Cell 45: 649-657.

Basler, K. and E. Hafen. 1988. sevenless and Drosophila eye development: A tyrosine kinase controls cell fate. Trends Genet. 3: 74-79.

Bishop, J.M. 1987. The molecular genetics of cancer. Science 235: 305-311.

Chabot, B., D.A. Stephenson, V.M. Chapman, P. Besmer, and A.
Bernstein. 1988. The proto-oncogene c-kit encoding a transmembrane tyrosine kinase receptor maps to the mouse $W$ locus. Nature 335: 88-89.

Church, G.M. and W. Gilbert. 1984. Genomic sequencing. Proc. Natl. Acad. Sci. 81: 1991-1995.

Coulier, F., D. Martin-Zanca, M. Ernst, and M. Barbacid. 1989. Mechanism of Activation of the Human trk oncogene. Mol. Cell. Biol. 9: 15-23.

Dollé, P., J.-C. Izpisua-Belmonte, H. Falkenstein, A. Renucci, and D. Duboule. 1989. Coordinate expression of the murine Hox-5 complex homoeobox-containing genes during limb pattern formation. Nature 342: 767-772.

Downward, J., Y. Yarden, E. Mayes, G. Scrace, N. Totty, P. Stockwell, A. Ullrich, J. Schlessinger, and M.D. Waterfield. 1984. Close similarity of epidermal growth factor receptor and v-Erb-B oncogene protein sequences. Nature 307: 521 527.

Geissler, E.N., M.A. Ryan, and D.E. Housman. 1988. The dominant-white spotting (W) locus of the mouse encodes the c-kit proto-oncogene. Cell 55: 185-192.

Hafen, E., K. Basler, J.E. Edstroem, and G.M. Rubin. 1987. sevenless, a cell-specific homeotic gene of Drosophila, encodes a putative transmembrane receptor with a tyrosine kinase domain. Science 236: 55-63.

Hanks, S.K., A.M. Quinn, and T. Hunter. 1988. The protein kinase family: Conserved features and deduced phylogeny of the catalytic domains. Science 241: 42-52.

Hogan, B., F. Costantini, and E. Lacy. 1986. Manipulating the mouse embryo: A laboratory manual. Cold Spring Harbor Laboratory Press, Cold Spring Harbor, New York.

Holland, P.W.H. and B.L.M. Hogan. 1988. Expression of homeo box genes during mouse development: A review. Genes Dev. 2: $773-782$.

Jackson, I.J., P. Schofield, and B. Hogan. 1985. A mouse homoeo box gene is expressed during embryogenesis and in adult kidney. Nature 317: 745-748.

Jakobovits, A., M. Schwab, J.M. Bishop, and G.R. Martin. 1985. Expression of $\mathrm{N}-m y c$ in teratocarcinoma stem cells and mouse embryos. Nature 318: 188-191.

Jakobovits, A., G.M. Shackleford, H.E. Varmus, and G.R. Martin. 1986. Two proto-oncogenes implicated in mammary carcinogenesis, int -1 and int -2 , are independently regulated during mouse development. Proc. Natl. Acad. Sci. 83: $7806-7810$.

Joyner, A.L., T. Kornberg, K.G. Coleman, D.R. Cox, and G.R. Martin. 1985. Expression during embryogenesis of a mouse gene with sequence homology to the Drosophila engrailed gene. Cell 43: 29-37.

Katzav, S., D. Martin-Zanca, and M. Barbacid. 1989. vav a novel human oncogene derived from a locus ubiquitously expressed in hematopoietic cells. EMBO J. 8: 2283-2290.

Klein, R., L.F. Parada, F. Coulier, and M. Barbacid. 1989. trkB, a novel tyrosine protein kinase receptor expressed during mouse neural development. EMBO J. 8: 3701-3709.

Klein, R., D. Martin-Zanca, M. Barbacid, and L.F. Parada. Expression of the tyrosine kinase receptor gene $t r k B$ is confined to the murine embryonic and adult nervous system. Development (in press).

Krieg, P.A. and D.A. Melton. 1987. In vitro RNA synthesis with SP6 RNA polymerase. Methods Enzymol. 155: 397-415.

Land, H., L.F. Parada, and R.A. Weinberg. 1983. Cellular oncogenes and multistep carcinogenesis. Science 222: 771-778.

Lawson, S.N., K.W.T. Caddy, and T.J. Biscoe. 1974. Development of rat dorsal root ganglion neurones. Cell Tiss. Res. 153: $399-413$.

Le Douarin, N.M. 1982. The neural crest. Cambridge Univer- 
sity Press, Cambridge, England.

. 1986. Cell line segregation during peripheral nervous system ontogeny. Science 231: 1515-1522.

Maniatis, T., E.F. Fritsch, and J. Sambrook, 1982. Molecular cloning: A laboratory manual. Cold Spring Harbor Laboratory Press, Cold Spring Harbor, New York.

Martin-Zanca, D., S.H. Hughes, and M. Barbacid. 1986a. A human oncogene formed by the fusion of truncated tropomyosin and protein tyrosine kinase sequences. Nature 319: $743-748$.

Martin-Zanca, D., G. Mitra, L.K. Long, and M. Barbacid. 1986b. Molecular characterization of the human trk oncogene. Cold Spring Harbor Symp. Quant. Biol. 51: 983-992.

Martin-Zanca, D., R. Oskam, G. Mitra, T. Copeland, and M. Barbacid. 1989. Molecular and biochemical characterization of the human trk proto-oncogene. Mol. Cell. Biol. 9: 24-33.

Muller, R. 1986. Proto-oncogenes and differentiation. Trends Biochem. Sci. 11: 129-132.

Mullis, K.B. and F.A. Faloona. 1987. Specific synthesis of DNA in vitro via a polymerase-catalyzed chain reaction. Methods Enzymol. 155: 335-350.

Nusse, R. 1988. The int genes in mammary tumorigenesis and in normal development. Trends Genet. 4: 291-295.

Park, M., M. Dean, C.S. Cooper, M. Schmidt, S.J. O'Brien, D.G. Blair, and G.F. Vande Woude. 1986. Mechanism of met oncogene activation. Cell 45: 895-904.

Pulciani, S., E. Santos, A.V. Lauver, L.K. Long, S.A. Aaronson, and M. Barbacid. 1982. Oncogenes in solid human tumors. Nature 300: $539-542$.

Robertson, E.J. 1987. Embryo-derived stem cell lines. Teratocarcinomas and embryonic stem cells: A practical approach, pp. 71-112. IRL Press, Washington, D.C.

Roussel, M.F., T.J. Dull, C.W. Rettenmier, P. Ralph, A. Ullrich, and C.J. Sherr. 1987. Transforming potential of the c-fms proto-oncogene (CSF-1 receptor). Nature 325: 549-552.

Sieber-Blum, M. 1989. Commitment of neural crest cells to the sensory neuron lineage. Science 243: 1608-1611.

Silvers, W.K. 1979. White-spotting, patch and rump-white. In: The new coat colors of mice: A model for gene action and interaction, pp. 206-241. Springer-Verlag, New York.

Sprenger, F., L.M. Stevens, and C. Nusslein-Volhard. 1989. The Drosophila gene torso encodes a putative receptor tyrosine kinase. Nature 338: 478-483.

Theiler, K. 1972. The house mouse: Development and normal stages from fertilization to 4 weeks of age. Springer-Verlag, Berlin, Heidelberg.

Weinberg, R.A. 1985. The action of oncogenes in the cytoplasm and nucleus. Science 230: 770-776.

Wilkinson, D.G., J.A. Bailes, and A.P. McMahon. 1987. Expression of the proto-oncogene int-1 is restricted to specific neural cells in the developing mouse embryo. Cell 50: 7988.

Wilkinson, D.G., G. Peters, C. Dickson, and A.P. McMahon. 1988. Expression of the FGF-related proto-oncogene int-2 during gastrulation and neurulation in the mouse. EMBO I. 7: 691-695.

Wilkinson, D.G., S. Bhatt, M. Cook, E. Boncinelli, and R. Krumlauf. 1989. Segmental expression of Hox-2 homoeobox-containing genes in the developing mouse hindbrain. Nature 341: 405-409.

Yarden, Y., W. Kuang, T. Yang-Feng, and A. Ullrich. 1987. Human proto-oncogene c-kit: A new cell surface receptor tyrosine kinase for an unidentified ligand. $E M B O \quad I$. 6: $3341-3351$.

Zimmerman, K.A., G.D. Yancopoulos, R.G. Collum, R.K. Smith, N.E. Kohl, K.A. Denis, M.M. Nau, O.N. Witte, D.
Toran-Allerand, C.E. Gee, J.D. Minna, and F.W. Alt. 1986. Differential expression of myc family genes during murine development. Nature 319: 780-783. 


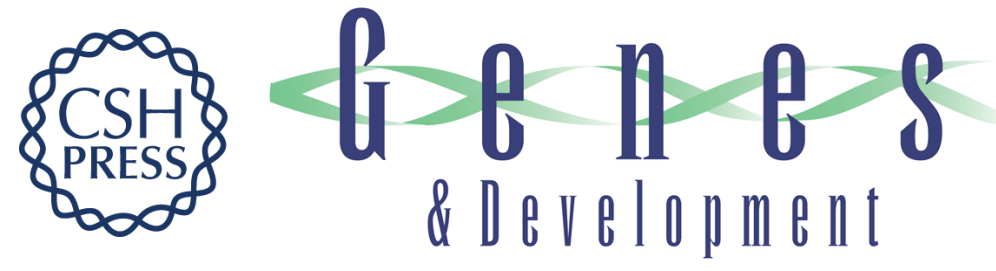

\section{Expression of the trk proto-oncogene is restricted to the sensory cranial and spinal ganglia of neural crest origin in mouse development.}

D Martin-Zanca, M Barbacid and L F Parada

Genes Dev. 1990, 4:

Access the most recent version at doi:10.1101/gad.4.5.683

References This article cites 41 articles, 13 of which can be accessed free at: http://genesdev.cshlp.org/content/4/5/683.full.html\#ref-list-1

License

Email Alerting Service

Receive free email alerts when new articles cite this article - sign up in the box at the top right corner of the article or click here.

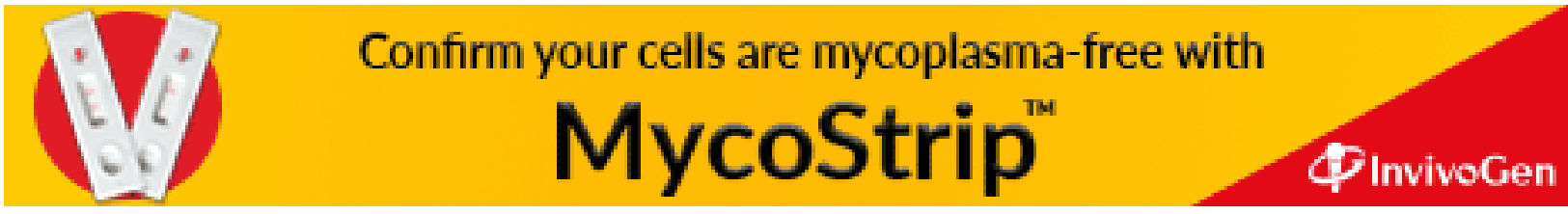

